\title{
Simulation guided value stream mapping and lean improvement: A case study of a tubular machining facility
}

\author{
Wei Xia, Jiwen Sun* \\ East China Institute of Computer Technology, Dept. of Industrial Engineering and Management, \\ Shanghai JiaoTong University (China) \\ stewensun@yahoo.com.cn *Corresponding author
}

Received: August 2012

Accepted: January 2013

\section{Abstrad:}

Purpose This paper describes a typical Value stream mapping (VSM) application enhanced by the discrete event simulation (DES) to a dedicated tubular manufacturing process.

Design/Methoddogy/A pproadr VSM is prescribed as part of lean production portfolio of tools, not only highlights process inefficiencies, transactional and communication mismatches, but also guides improvement areas. Meanwhile, DES is used to reduce uncertainty and create consensus by visualizing dynamic process views. It is served as a complementary tool for the traditional VSM to provide sufficient justification and quantifiable evidence needed to convince the lean approaches. A simulation model is developed to replicate the operation of an existing system, and that of a proposed system that modifies the existing design to incorporate lean manufacturing shop floor principles.

Findings: A comprehensive model for the tubular manufacturing process is constructed, and distinctive scenarios are derived to uncover an optimal future state of the process. Various simulation scenarios are developed. The simulated results are acquired and investigated, and they are well matched with the real production data.

Originality/Value DES is demonstrated as a guided tool to assist organizations with the decision to implement lean approaches by quantifying benefits from applying the VSM. A roadmap is 
provided to illustrate how the VSM is used to design a desired future state. The developed simulation scenarios mimic the behavior of the actual manufacturing process in an intuitive manner.

Keywords: value stream mapping, discrete event simulation, capacity analysis, layout modification, lean manufacturing, tubular machining

\section{Introduction}

The ultimate goal of lean manufacturing is to reduce waste in manpower, inventory, time to market, to become highly responsive to customer demand while producing quality products in a most efficient and economical manner (Womack \& Jones, 1996). It is well known that seven types of waste generally occur (Sullivan, McDonald \& Van Aken, 2002), as listed in Table 1. Visualizing the flow creates the ability to see where, when, and how both the information and product flows through, and consequently recognize and eliminate the source of waste. Unfortunately, many manufacturers have failed to fully understand this in their initial excitement and eagerness to start with the lean approaches. The implementation of these approaches involves more than just applying individual concepts like Kanban, layout planning, visual control, and takt time calculations (Barker, 1994). Typically, such organizations sporadically carry out these activities without linking their efforts to a systematic framework.

\begin{tabular}{|l|l|}
\hline \multicolumn{1}{|c|}{ Waste } & \multicolumn{1}{c|}{ Description } \\
\hline Overproduction & Producing too much or too soon, resulting in poor flow of information or products \\
\hline Unnecessary inventory & $\begin{array}{l}\text { Excessive storage and delay of information or products, resulting in excess } \\
\text { inventory, leading to a high holding cost and poor customer service }\end{array}$ \\
\hline Waiting & $\begin{array}{l}\text { Long periods of inactivity of people, information or products, resulting in poor flow } \\
\text { and long lead times }\end{array}$ \\
\hline Excessive transportation & $\begin{array}{l}\text { Excessive movement of people, information or products, resulting in wasted time } \\
\text { and cost }\end{array}$ \\
\hline Defects & $\begin{array}{l}\text { Frequent errors in paperwork, material, final product quality problems, resulting in } \\
\text { scrap and/or rework, as well as poor delivery performance }\end{array}$ \\
\hline Ineffective Motion & $\begin{array}{l}\text { Process is not well designed so that the operator will waste much more time for } \\
\text { excess motions to handle the process }\end{array}$ \\
\hline Inappropriate processing & $\begin{array}{l}\text { Process itself is inappropriate caused by using the wrong set of tools, procedures or } \\
\text { systems }\end{array}$ \\
\hline
\end{tabular}

Table 1. Seven types of waste

A critical assessment of many lean tools suggests that a key weakness is absence of visual nature, i.e., the ability of people with knowledge of lean techniques to explain the current dynamics of the organization, and to communicate an action plan that would be understood by 
all key stake-holders. There is a need to develop a more systematic means to help guide these lean tools and activities. Value stream mapping (VSM) is vigorously capable of undertaking this role. It not only highlights process inefficiencies, transactional and communication mismatches, but also guides the improvement area.

A value stream is a collection of all actions (both value-added and non-value-added) that are required to bring a product or a product family that use the same resources through the main flows, starting with raw material and ending with the customer (Childerhouse \& Towill, 2002). The VSM is defined as 'the simple process of directly observing the flows of information and materials as they now occur, visually summarizing them, and then envisioning a future state with much better performance' (Jones \& Womack, 2000). The primary objective of the VSM is to identify all kinds of waste in the value stream and to take actions to eliminate these (Rother \& Shook, 1999). While researchers have created numerous lean tools to optimize individual operations, most of them fall short in linking and visualizing the material and information flow throughout the entire process (Pavnaskar, Gershenson \& Jambekar, 2003). The VSM creates a common basis for the process, thus facilitates more thoughtful decisions to improve it (McDonald, Van Aken \& Rentes, 2002). This helps plan and link lean initiatives through systematic data capture and analysis. The VSM has emerged as the preferred way to implement lean approaches, both inside facilities and at the supply chain level linking those facilities (Hines \& Rich, 1997). This unique mapping method facilitates visualization of the cycle times, inventory at each stage, human effort and information flow. The current or 'as is' status is mapped to capture a snapshot of how things are done and where the improvement solutions lie, and the future or 'to be' state map is then built to show how things should be done considering potential requirements.

For traditional manufacturers, the reluctance to implement lean tools arises since their distinctive requirements recurrently make it hard to predict the gain magnitude achieved by doing so. It is an endeavor also due to the difficulty in changing aspects including raw material procurement, inventory management, production control, and facility layout. Therefore, managerial decisions often rely on the reported results of others who have implemented, or heuristic rules of thumb on the expected benefits. It is always an insufficient justification, and lacks the quantifiable evidence needed to convince them to adopt lean (Detty \& Yingling, 2000). While in some situations the future state map can be evaluated with relatively modest effort, it is not as straightforward to do so in many others. In general, a complementary tool is imperative for the VSM to quantify the gains during planning and assessment stages.

VSM has long been viewed as a paper-and-pencil means. It is literally drafted by answering specific questions on issues related to efficiency and on technical lean tool implementation, as listed in Table 2 (Rother \& Shook, 1999). In some cases, however, the future state map cannot be designed by solely doing so in a frank manner. For instance, predicting the inventory flows and levels is impossible with only static data. Most currently reported VSM applications do not 
appear to utilize simulation. Developing a useful simulation model tends to be a lengthy and time consuming task, not well aligned with the relatively quicker cycle time. Therefore, simulation may not be viewed as worth the endeavor. As an extensively used process modeling tool, however, simulation is often used to reduce uncertainty and create consensus by visualizing dynamic process views for a given future state. Additionally, it helps explore alternatives generated by different responses to those design questions. Simulation is capable of generating resource requirements and performance statistics whilst remaining flexible to specific organizational details.

\begin{tabular}{|c|c|}
\hline Level & Questions \\
\hline Basic & $\begin{array}{l}\text { 1. What is the takt time? } \\
\text { 2. Will finished goods be built to replenish a supermarket, or will they be built and } \\
\text { directly shipped to customers? } \\
\text { 3. Where can continuous flow processing be utilized? } \\
\text { 4. Is there a need for a supermarket pull system within the value stream? } \\
\text { 5. What single point in the production line will be used to schedule production? }\end{array}$ \\
\hline $\begin{array}{l}\text { Heijunka } \\
\text { (Leveling Production) }\end{array}$ & $\begin{array}{l}\text { 6. How will the production be leveled at the pacemaker process? } \\
\text { 7. What increment of work will be consistently released from the pacemaker process? }\end{array}$ \\
\hline Kaizen (Improvement) & 8. What process improvement will be needed? \\
\hline
\end{tabular}

Table 2. Design questions for value stream mapping

Discrete event simulation has been considered as one of the most flexible analytical tools in the manufacturing system design and operation areas. It is aggressively used to handle uncertainty and create dynamic views of lead time and machine utilization. This enables quantification of results, and provides a possibility to compare the expected performance relative to that of the present one. It thus can be used to assist organizations with the decision to implement the VSM by quantifying benefits from applying lean principles in their specific situation. There is a significant number of practitioner oriented papers in this area. The majority of them describe the use of simulation to analyze existing or planned manufacturing systems. Chan (1995) uses a simulation model to evaluate the performance of an automotive manufacturing system as a function of demand. Prakash and Chen (1995) develop a simulation model of a flexible manufacturing system to investigate the overall performance. Welgama and Mills (1995) analyze two cell designs for a manufacturing facility considering operator and material handling utilization factors. Cho, Moon and Yun (1996) use simulation to identify parameters to improve system performance at a motor production facility. Bischak (1996) describes simulation in evaluating the performance of a textile manufacturing module with moving workers. Park, Matson and Miller (1998) describe a simulation approach used to verify that daily throughput requirements can be met at a new assembly plant, and it is used to determine the maximum throughput of the facility and characterized how the component buffers behave in terms of quantity fluctuations and identified possible system bottlenecks. Shang and Tadikamalla (1998) use a combination of simulation and optimization to evaluate the design of a cellular manufacturing system. Persson (2002) investigate the impact of a 
varying level of system structure detail in modeling a manufacturing system. In addition to using simulation to directly analyze and predict system performance, some researchers have used simulation to validate analytical models that are in turn used for studying underlying systems. Suri and Desiraju (1997) use simulation to validate analytical models and predict the system performance for a single material handling device case. There is not much work have been reported in context to value stream studies regarding manufacturing and simulation based methodology (Lian \& Van Landeghem, 2007). Additional and detailed examples of VSM simulation are badly needed in different types of actual production settings.

VSM differentiates itself from conventional recording approaches. It helps visualize cycle times, inventory buffers at intermediate stations, manpower deployment, uptime, and the information flow. Compared with the traditional manufacturing process simulation approaches, VSM provides several advantages. Firstly, it is not solely mapping the current status but a systematical methodology to understand the whole process, identifying and distinguishing value added and non-value added activities. Secondly, it offers a broader and system level view. The strategic, tactical and operational decisions are vertically coordinated. Lastly, it not only highlights process inefficiencies, transactional and communication mismatches, but also guides the improvement area. Simulation combined with the VSM offers a viable tool for evaluating the potential level of productivity gains which can be achieved using lean concepts. Generally, the VSM provides a structured format in which processes can be redesigned, and simulation offers a methodology for evaluating expected benefits from process redesign.

As can be seen, the VSM is a necessary but not a sufficient approach to analyze system issues. Deficiencies easily arise since it is a deterministic method and uses only descriptive maps to model production operations. These insufficiencies include incapability of modeling and assessing effects of variation, making use of all available data, validating effects of proposed modifications before implementation, identifying extra possible improvements, and assessing interactions between subsystems. Therefore, no mechanism is available to distinguish if the specifications it contains will produce the desired system behavior or achieve performance targets. Accordingly, simulation is strongly recommended to faithfully address operational issues that the VSM failed to identify and could not resolve.

The objective of this paper is to demonstrate the discrete event simulation as a guided tool to assist organizations with the decision to implement lean approaches by quantifying benefits from applying the VSM. A roadmap is provided to illustrate how the VSM is used to design a desired future state. A simulation model is developed to replicate the operation of an existing system, and that of a proposed system that modifies the existing design to incorporate lean manufacturing shop floor principles. Due to the nature of the discrete event simulation, the developed simulation scenarios mimic the behavior of the actual manufacturing process in an intuitive manner. It is also explored through an industrial example how the simulation modeling is applied. The remainder of the paper is organized as follows: Section 2 gives an 
overview of the methodology. Section 3 explores the simulation process used in support of constructing and investigating current and future state. Finally, conclusions and future directions are provided in Section 4.

\section{Overview of methodology}

Discrete event simulation provides a valuable tool for the VSM implementation. First, the execution of a discrete event simulation model is based on an event or activity that occurs in the manufacturing process. Recent developments of the animation and data interface of simulation software allow VSM to be graphically presented and integrated into the existing company manufacturing information system. Secondly, simulation models the stochastic nature inherent in the manufacturing process when the highly significant and intrinsic variation and dynamic behavior is characterized. Simulation guided VSM is therefore a natural extension of existing VSM applications. A methodology of discrete event simulation guided value stream mapping using iGrafx software is proposed. A comprehensive simulation model is developed to replicate the operation of an existing system, and the proposed new system with a modified design to incorporate lean manufacturing shop floor principles.

A systematic approach is followed to develop the VSM and optimize the facility. First, Data collection and validation is undertaken to form the current state scenario and verify the proposed model. Then, capacity calculation and layout modification for the future state map are investigated. Finally, the simulation model and various scenarios are generated and the future state map is proposed. Details of the methodology are as follows.

Initially, the routing time data are received from the company. The outputs of calculations and computer models are only as good as the inputs, and inaccurate data guarantees meaningless outputs. Therefore, considerable time is spent on the shop floor observing the whole manufacturing process to confirm the consistency of the time data with the reported one. The products are differentiated by length, diameter, and material. With all the part numbers, it is impossible to clock times for each one. However, the machining operations required to finish the products are similar. The validation is only carried out for the parts that are actually flowing through the manufacturing process. The recorded routing times of around 20 types of products are compared with the data provided. Overall, the reported data is accurate enough for further simulation.

To evaluate the potential gains, a detailed simulation model is constructed by using iGrafx software. It offers various process analysis solutions that help document, analyze and improve their operations. Specifically, it is used to create value stream maps, flow charts, to serve as a comprehensive model constructor to run manufacturing process simulations. There are twofold purposes in using this software. First, the VSM can be drawn according to various standard shapes and line styles available from its toolbar and gallery. Second, the 'behind screen' algorithm will be described by creating a process model, displaying as a flow chart. After 
having drawn the process steps and flow, one can enter data associated with each object to mark its distinctive properties. In general, building a simulation model and process by using iGrafx involves several basic activities: (1) Create a process model diagram using departments, shapes, and connector lines; (2) Describe the behavior of each activity; (3) Construct the simulation environment the process lives in through the scenario; and (4) Execute a simulation and analyze the results. In general, a process model is developed which consists of activities, resources, and business rules that govern process behavior. Transactions arrive at the input of an activity from a data generator, and resources may perform a task on each transaction. When the task is completed, the transaction output serves as the input of the next activity through a connector line. The software gathers statistics during simulation on resource utilization, cycle time, costs, capacity, and other pre-defined and customizable statistics.

Verification is a highly necessary step that ensures the simulation model sufficiently represents and adequately replicates the real system. This includes careful trace studies, detailed animation to verify proper system behavior, and a review of the model behavior via animation and numerical output. Due to the nature of discrete event simulation, the developed simulation mimics the behavior of the actual manufacturing process in an intuitive manner. This mimic behavior enables the management and operators to understand the logic with clarity. Since it is a large model with many types of input entities, confirmation is required that every kind of entities is traced and the corresponding model logic is checked to guarantee the required sequence is followed. The explicit representation of various entities and the sequence of events occurring in the tube manufacturing process make the simulation model both clear and easily extended to account for other aspects of the process. Several features are used by the simulation process, including variable run times actually assigned based on the machine and operator's experience; variable setup times assigned based on the previous and next part characteristics, such as part type, width, specifications; rules assigned for sequencing jobs at work centers, based on minimizing setup and other factors; and rules assigned for selecting from a list of prioritized jobs based on due date, slack, cost.

Actual data is available from the manufacturing execution information system. Dataset are from the first two quarters of 2011. It allows comparing the simulation results with the actual production throughputs to test its credibility. The model is rigorously validated and is found to faithfully represent the actual manufacturing process. It is quite satisfied that the numerical outputs from the simulation are all within the range of the actual data. The throughput and work-in-progress (WIP) levels from the model well match with the actual production data. This accuracy gives the management confidence not only in the designated simulation software and the developed algorithm in simulation modeling, but also their potential as a decision-making tool.

The current and future state capacity scenarios are acquired by experimenting with different machine combinations and shift patterns. These scenarios are primarily developed according to 
theoretical and practical considerations. The theoretical one concerns about mathematical parameters, such as machine capacity, machine configurations (addition or subtraction of certain machine type, machine combination), shift patterns. The primary goal is to balance throughput, WIP and production lead time. These constraints account for real considerations of the machine configurations, working time availability and permission. For example, the machine configurations consider the addition of a third mill in the current phase and a third group of lathe (two together) in the near future, such as one-old-one-new-Mills, one-new-Mill, two-old-one-new-Mills, two-old-Mills, and their combinations with the third group of lathe, respectively. According to individual capacity, each machine is responsible to work with different shift patterns. It is another constraint for developing scenarios. While practical considerations include the machine budget, shop floor layout and space, conveyor connections, labor shift and holiday, machining capability of certain machine as well.

Upon the initial analysis is completed and all the different scenarios are compared, some of which can be served as realistic candidates are selected. Several unrealistic and similar candidates are thus not chosen. Only some vital and distinctive scenarios are selected to mark the different working conditions. The final step is to simulate the potential future state scenarios and ultimately select an optimal future state scenario for the future state map.

\section{Enhancing value stream mapping with simulation}

To assess the validity of the proposed method, a real manufacturing process is thoroughly analyzed and a possible lean solution is presented. This application is implemented within a domestic manufacturing facility. Specifically, the plant is devoted to tubular machining. The organization's identity is protected and those related information shall not be released, so a part of the information is altered. In the remainder of the paper, it will be simply referred to as the company.

The activity in the complex manufacturing process is governed by human designed operational rules. The dynamics of this process are characterized by asynchronous occurrences of discrete events such as the arrival or departure of a job, or the initiation and completion of a designated manufacturing task. Therefore, the discrete event simulation can be well used in this case study. Although the major disadvantage of this simulation approach as opposed to an ordinary analytical approach is its cumbersome cost and computation intensity. The simulation is more accurate since it is not developed based on as many assumptions as analytical procedures. The VSM firstly identifies value added and non-value added activities, which makes the simulation focus on some key activities and much easier to conduct.

The company started to fully manufacture in 2008, and it now produces approximately 1600 units of tubes per month with all kinds of specifications. Each final product consists of an outer tube and an inner tube, which are called carrier and loading tube, respectively. Therefore, two separate production lines are designed, one for carriers and the other for loading tubes. At the 
end of the tubular manufacturing process, the loading tube is manually inserted into the carrier to form the final assembly. It is then packed and sent out to the appropriate location. The company manufactures all the carriers in-house whilst fabricates only $50 \%$ of its loading tubes and outsources the remainder to local suppliers. The facility layout and its associated manufacturing process are illustrated in Figure 1. The key manufacturing procedures for the carrier are from sawing, through lathing and milling, to assembly and packing. The sequence for the loading tube is from laser cutting to welding. There are two parallel lathe lines, and each one is equipped with two identical lathes. According to the technical specification, the carrier is sequentially flowed from the first lathe for machining one end and the keyway, then through the second lathe for the other end without a keyway.

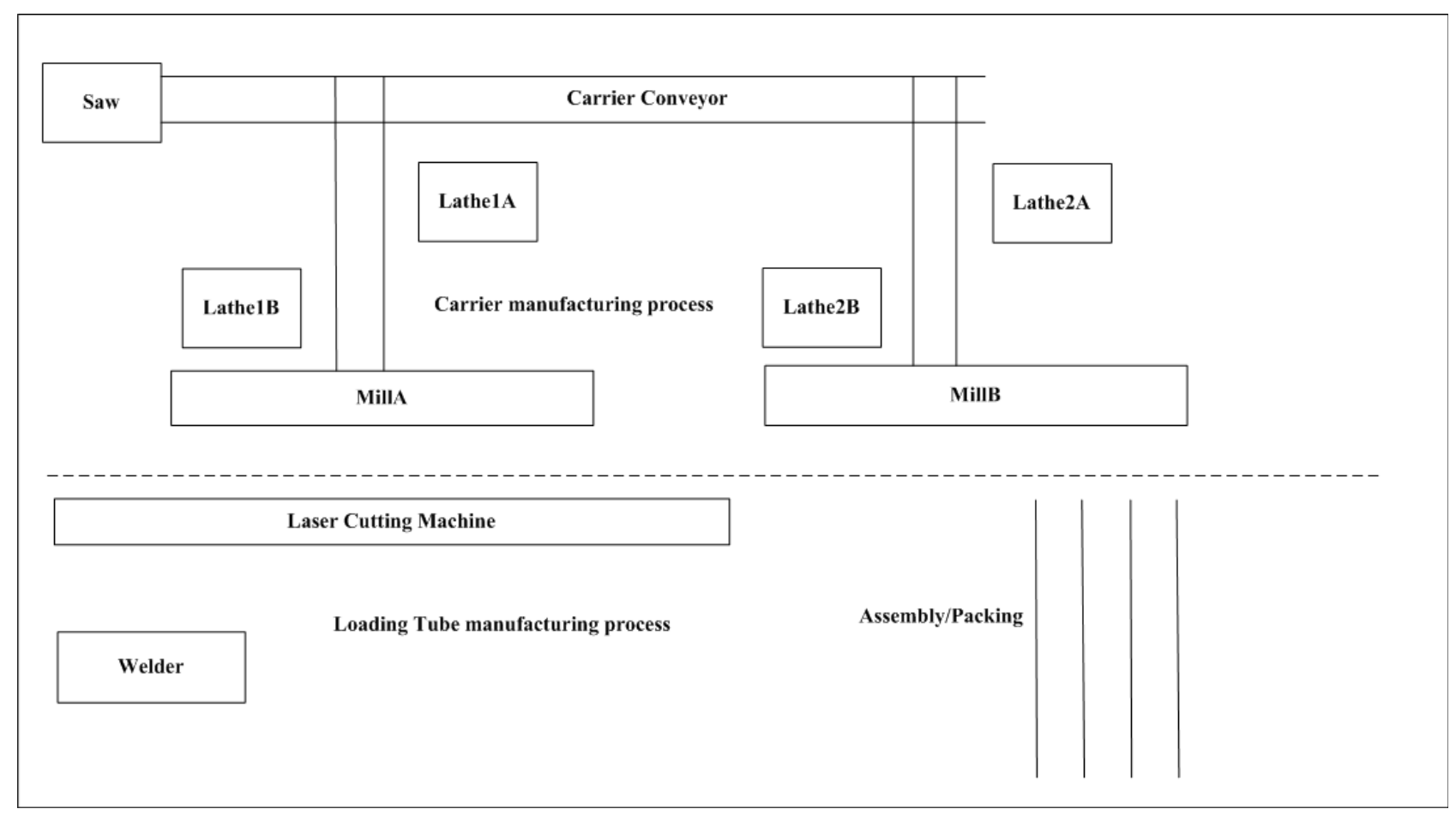

Figure 1. Current facility layout plan

It is not straightforward to answer the impact issue with the VSM alone. Several factors need to be seriously considered, including the number of different product families produced, various processing times and setup times for each operational step, distinct shift patterns for each work station, and serial-parallel processing paths through the production line as well. These factors together create a complexity that cannot be addressed by using the VSM alone.

A comprehensive simulation model is built to thoroughly understand the manufacturing process, as illustrated in Figure 2. The simulation model incorporates several distinctive features. For example, each work station processes parts based on its individual cycle times for each part number. Setup times are automatically included into the model when part numbers change. Time variability is also considered with designated normal distribution, including variability of arrival rate, cycle times, setup times, and move times. Additionally, shift patterns are accounted to be consistent with the real work schedules (including exact break time) and 
the availability of individual workers. Furthermore, Machine uptime and unscheduled machine breakdowns are incorporated.

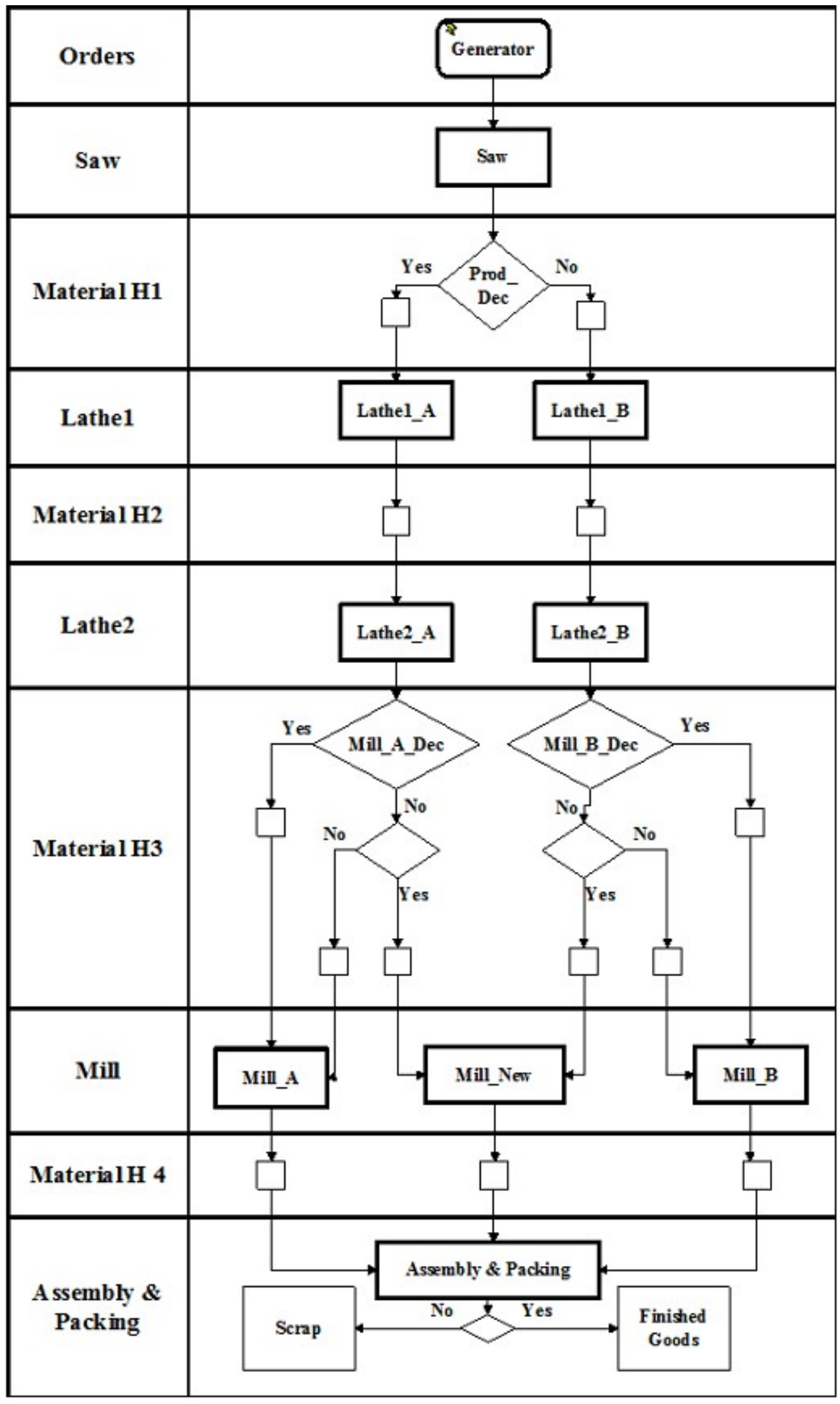

Figure 2. iGrafx simulation model 
Simulations are carried out by using actual production orders of the first two quarters of 2011 flowing through the production system. Orders are fed into the model through the inter-arrival generator on the top of the model and one can choose this rate at which they arrive. At each work station, the carrier machining transaction is processed according to its individual cycle time with appropriate variability. If a part number changes, the model accounts for the setup time. The diamond shapes represent decision logic, and they are used to route the carriers to the desired work stations according to the predefined constraints.

By using this model, numerous "what-if" scenarios are tested and one is deemed optimal. These scenarios are distinctive in various features, including addition or subtraction of machines, balancing of work shifts, using different arrival rates. The simulated results are used to understand accumulation of WIP before and after each machine, to compare the machine efficiency, to properly account for variability. It is utilized to balance throughput, WIP and production lead time. Overall, the simulation model is served as a general tool for future shift, product mix and expansion decisions.

\subsection{Current state VSM}

The current state VSM is concurrently drafted while investigating the simulation model based on the verified data, as shown in Figure 3. Those small boxes represent the machining process, and the number inside the box is the number of machines at each process. Also, each process has a data box below, which contains the process cycle time, machine availability, the number of shifts, and the changeover time. It is clear that the current state VSM shows various vital details like work station cycle time, uptime and time available in each shift. The triangle with a letter ' $I$ ' inside represents the inventory piled up at various stages. Essentially, it summarizes information about actual value-added time and total production lead time. The visualization of different times and other factual findings gives an actual trigger and offers a challenge for future improvement. It should be noted that the processing and setup times are collected whilst staying and recording on the shop floor and discussing with the manufacturing supervisor and operators at each workstation.

Based on the demand forecast, a weekly schedule is generated for each stream of the process to push orders through production. Additionally, a supervisor is in charge to control production, make daily adjustments to solve any possible problems, and fulfill any urgent orders. A systematic procedure for the VSM is followed before the simulation, where a series of structured questions is answered. This allows one to envisage an ideal future state map that will help eliminate or at least reduce different types of waste in the current manufacturing system.

The manufacturing capacity is previously not well understood, and it causes a large and unorganized WIP inside the facility. Originally, two mills are used for the carrier manufacturing process. A third more powerful and efficient mill is introduced recently to strengthen and 
balance the capacity. A question is raised whether to eliminate one, both or neither of the old mills. Also, as production increasingly shifts to the company, there is a need for a clear understanding of its current and future state production capabilities. The relationship between throughput, WIP and production lead time are explored, and numerous combinations of production lines, the number of machines and shift patterns are considered.

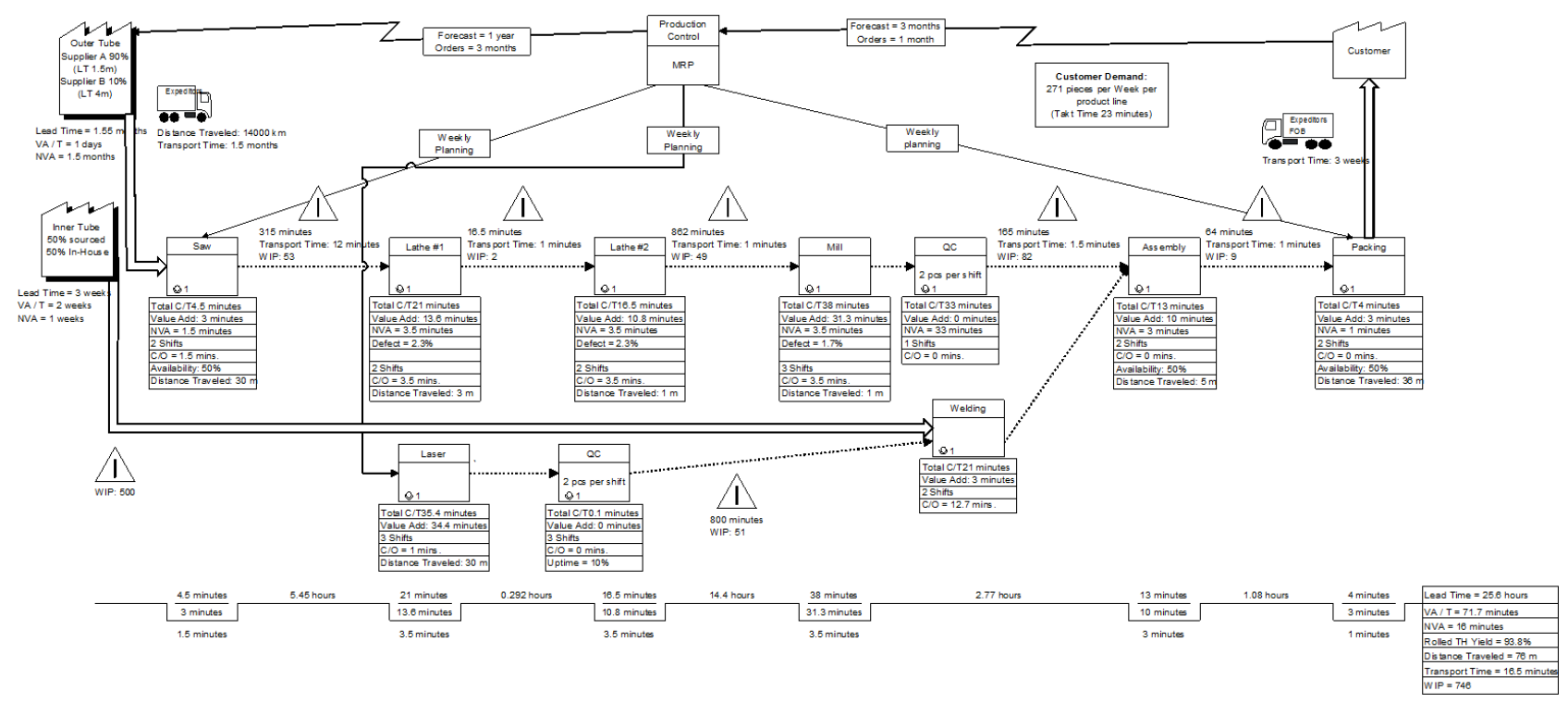

Figure 3. Current state VSM

After running a multitude of simulations, two scenarios are selected as the optimal future states. The capacity analysis of one-old-one-new mills scenario is described in Table 3 . The detailed machine performance can be referred to the Table A1 in the Appendix. If the company retains its current structure of just two lathe lines, it is concluded that the one-old-one-new mills scenario provides the best overall performance. Under these circumstances, there is no need to operate all three mills.

\begin{tabular}{|l|c|c|c|c|c|}
\hline \multicolumn{1}{|c|}{ Parameters } & Saw & Lathe 1 & Lathe 2 & Mill & Assembly/Packing \\
\hline Cycle time (min) & 3.0 & 17.1 & 13.0 & 15.0 & 6.0 \\
\hline Setup time (min) & 1.5 & 3.0 & 3.0 & 1.1 & 0.0 \\
\hline Total time (min) & 4.5 & 20.1 & 16.0 & 16.1 & 6.0 \\
\hline Shifts & 2 & 3 & 3 & 3 & 2 \\
\hline Break time (min) & 60 & 60 & 60 & 60 & 60 \\
\hline Operators & 1 & 1 & 1 & 1 & 4 \\
\hline Uptime & $97.0 \%$ & $90.0 \%$ & $83.5 \%$ & $93.0 \%$ & $97.0 \%$ \\
\hline Number of Machines & 1 & 2 & 2 & 2 & 1 \\
\hline Scrap rate & $0.0 \%$ & $2.3 \%$ & $2.3 \%$ & $1.7 \%$ & $0.0 \%$ \\
\hline Capacity & 181 & 110 & 128 & 143 & 136 \\
\hline
\end{tabular}

Table 3. Capacity analysis of one old one new Mills scenario

The relationship between the WIP and the throughput is demonstrated in Figure 4, the maximum throughput expected for a 22-day period is approximately 2750 units. However, 
when comparing throughput, WIP and production lead time, the ideal situation to balance three factors is with a seven-minute arrival rate. With this pace, throughput is 2543 units per month, while WIP is relatively low at 74 units and production lead time averages about 15.1 hours, i.e. 844 minutes of wait time plus 60 minutes of actual production time. This renders a drastic improvement over the current state where monthly throughput is about 1600 units, WIP is over 700 units and production lead time is approximately 26 hours.

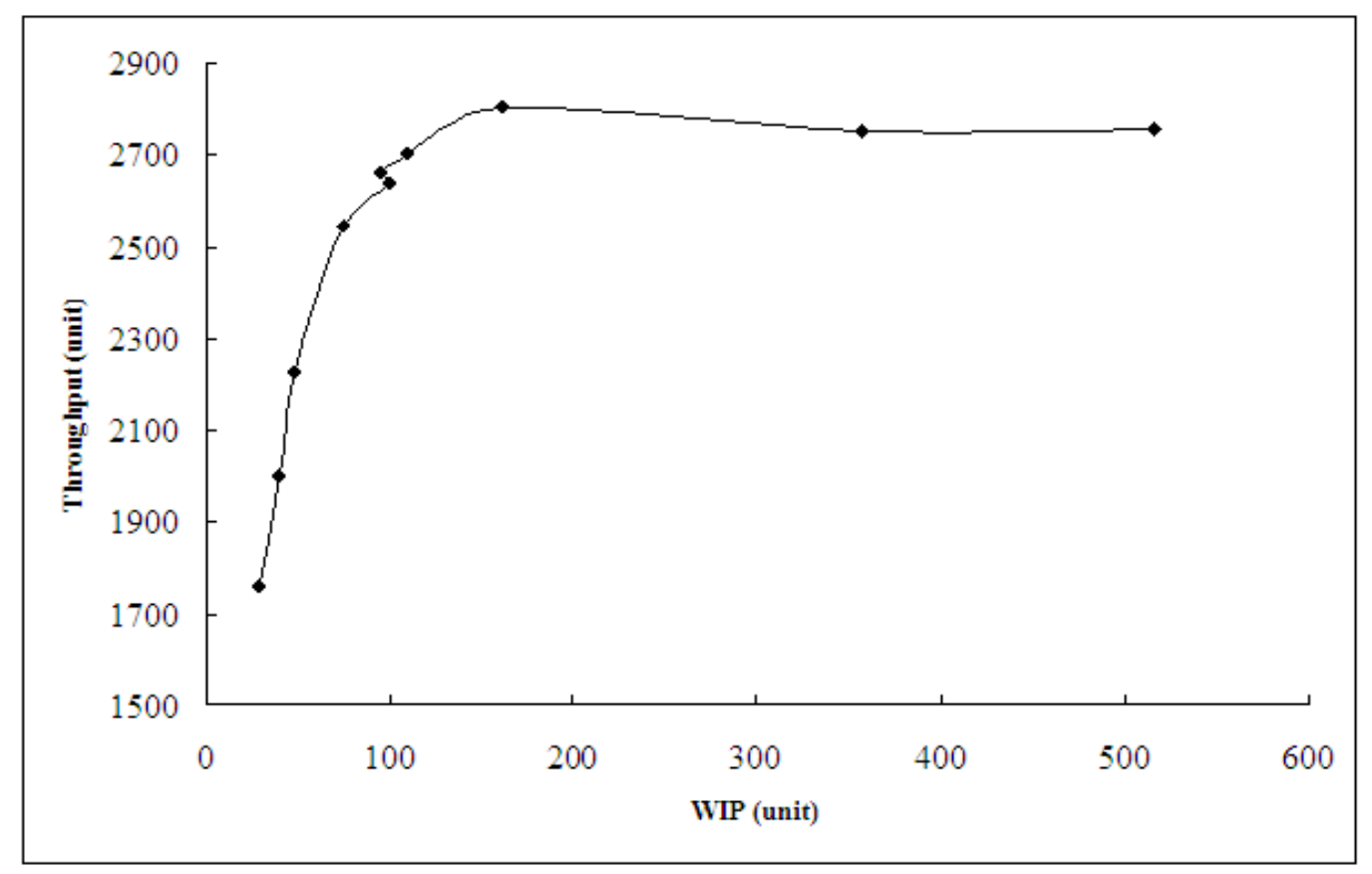

Figure 4. WIP vs. throughput of one old one new mills scenario

Another scenario is expected by the company to evaluate is the potential addition of a third set of lathes, since the lathes are now the process bottleneck. To understand the effect this new lathe line would have on the throughput and also how many mills would be necessary to properly balance the line, the capacity analysis is investigated, as outlined in Table 4. The detailed machine performance can be referred to the Table A2 in the Appendix.

\begin{tabular}{|l|c|c|c|c|c|}
\hline \multicolumn{1}{|c|}{ Parameters } & Saw & Lathe 1 & Lathe 2 & Mill & Assembly/Packing \\
\hline Cycle time (min) & 3.0 & 17.1 & 13.0 & 18.1 & 6.0 \\
\hline Setup time (min) & 1.5 & 3.0 & 3.0 & 1.4 & 0.0 \\
\hline Total time (min) & 4.5 & 20.1 & 16.0 & 19.6 & 3.0 \\
\hline Shifts & 2 & 3 & 3 & 3 & 60 \\
\hline Break time (min) & 60 & 60 & 60 & 60 & 4 \\
\hline Operators & 1 & 1 & 1 & 1 & $97.0 \%$ \\
\hline Uptime & $97.0 \%$ & $90.0 \%$ & $83.5 \%$ & $93.0 \%$ & 3 \\
\hline Number of Machines & 1 & 3 & 3 & 3 & $0.0 \%$ \\
\hline Scrap rate & $0.0 \%$ & $2.3 \%$ & $2.3 \%$ & $1.7 \%$ & 204 \\
\hline Capacity & 181 & 165 & 193 & 176 & \\
\hline
\end{tabular}

Table 4. Capacity analysis of three Lathes and three Mills scenario 
The maximum throughput expected for a 22-day period is approximately 3750 units, as illustrated in Figure 5. However, when leveraging throughput with WIP and production lead time, the optimal situation is with a five-and-a-half-minute arrival rate, leaving throughput of 3293 units per month. At this arrival rate, WIP is manageable at 75 units and production lead time averages about 16.4 hours, i.e. 927 minutes of wait time plus 60 minutes of actual production time. This throughput of 3300 units per month offers a $30 \%$ increase over that of the one-old-one-new mills scenario.

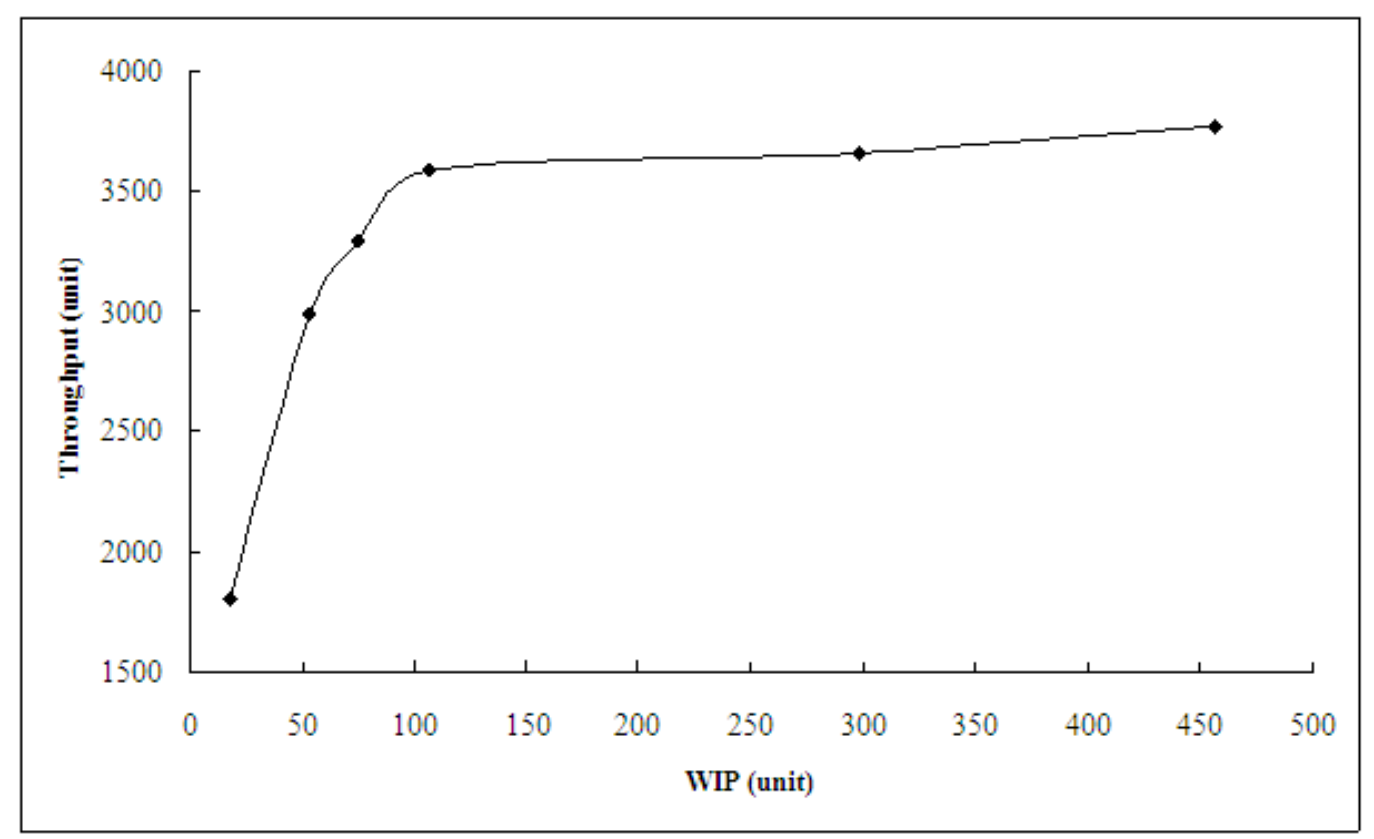

Figure 5. WIP vs. throughput of three lathes and three mills scenario

\subsection{Future state VSM}

The model is concretely used to answer the questions about the capacity and capabilities of the company and will help guide decisions for future expansion. Overall, the model is an excellent tool and if used intelligently, will provide various useful insights about the manufacturing process. It is equivalent to the 'factory inside a computer' with flexibility in a software environment. Furthermore, the layout recommendations are accompanied with the capacity analysis by using lean manufacturing principle, details can be referred to in the Appendix. They are well taken by the manufacturing engineers and management, and they have already been accepted and implemented. These changes will ensure a better material flow, especially in the assembly/packing area. Also, they will save time and space. As the demand is expected to rise, material flow will play an increasingly important role, and these modifications will help handle the higher production volume more efficiently. There is also a marketing advantage from being able to meet customer demand within shorter lead times.

Guided by these simulated results and modified layout plan shown in Figure 6 , the future state VSM is also constructed, as illustrated in Figure 7. Prior to adding a new mill, the total 
production rate is approximately 1600 per month on average. With the addition of the new mill, it is able to comfortably achieve monthly throughput of 2500 units for 22 working days, both saw and assembly/packing work two shifts a day, lathe and mill work three shifts a day. The company will only need one of its old mills and its new mill to reach this production level. Alternatively, if an additional lathe line is scheduled to incorporate, the third mill will need to operate in order to handle the volume flowing from the three lathe lines, for the purpose of leveling the production. With the addition of a third lathe line, the total production rate will be achieved to a level of approximately 3300 units, where the whole month is 22 working days, saw works two shifts a day, lathe, mill and assembly/packing work three shifts a day. It accomplishes an increase of $29.5 \%$ over the current state scenario.

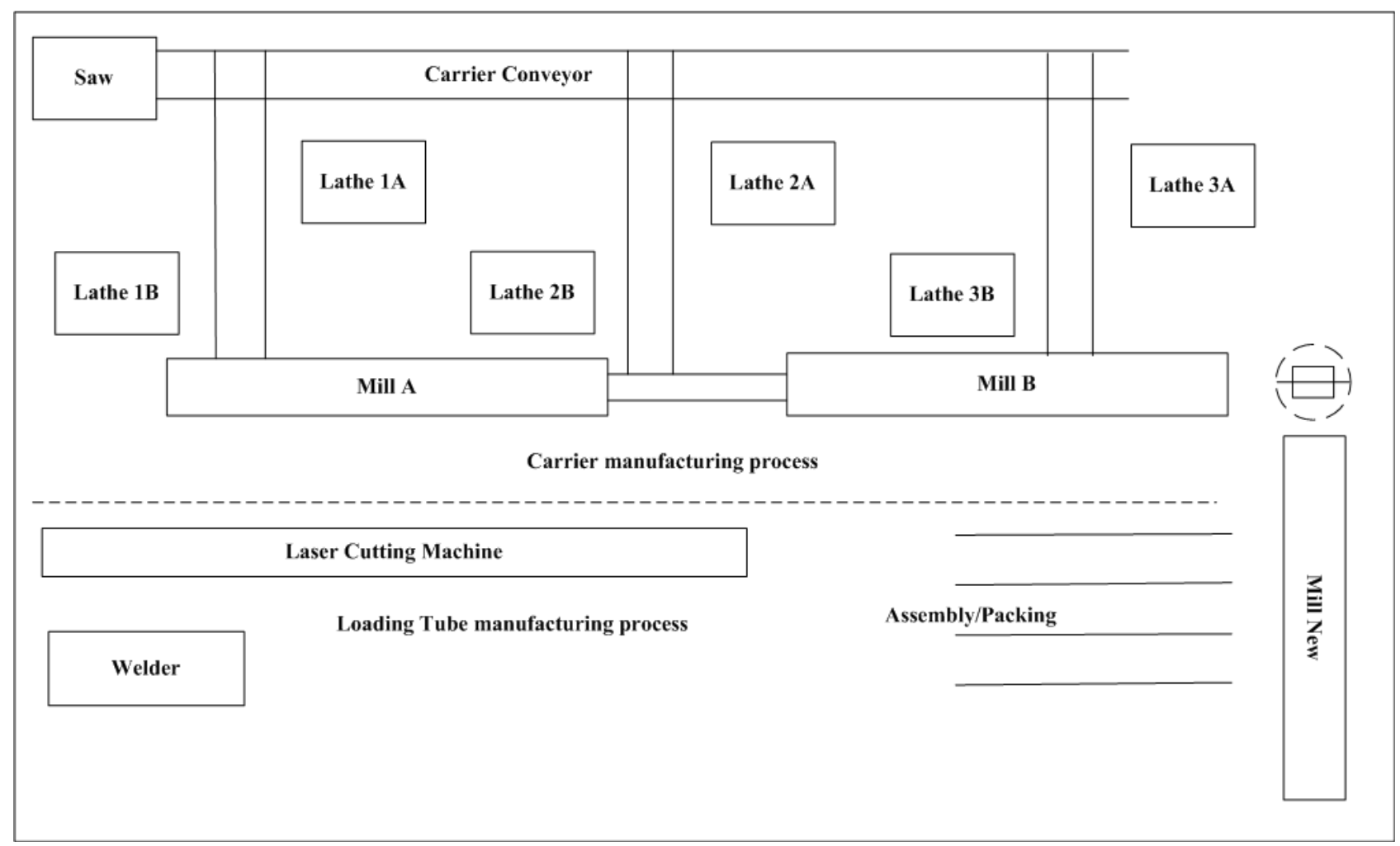

Figure 6. Layout modification of assembly/packing area

This industrial application has demonstrated that the discrete event simulation can be a useful part of the VSM. Although it is not proposing that simulation always be utilized with the VSM, it forms an integral part of the lean approach. Specifically, as found in this case, when there is product complexity which leads to differences in processing and setup times across product variants, parallel processing lines and different number of shifts used across a production line, simulation provides important information to complement that obtained from future state mapping. Furthermore, simulation facilitates process visualization, creating a shared consensus about the process and where improvement solutions can be made. 


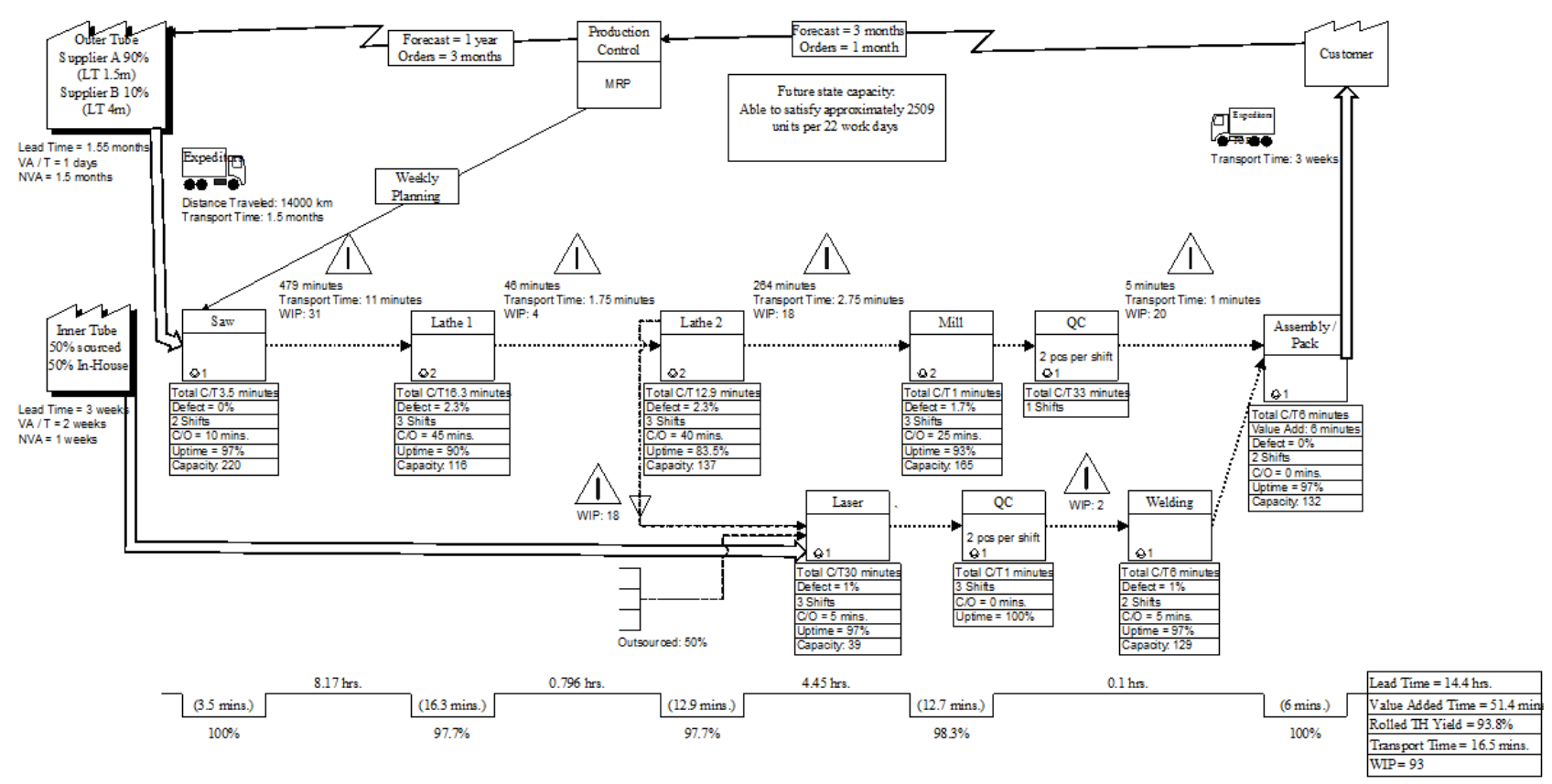

Figure 7. Future state VSM

This discrete event simulation guided VSM framework includes both the managerial and the operational aspects of the manufacturing process. Only then can management move beyond the traditional static performance analysis. This simulation guided VSM allows the management to differentiate between value added and non-value added activities, and it has the potential to be a strategic decision making tool for process redesign and continuous improvement. With the detailed information obtained from the simulation guided VSM, it is possible to determine if overall cost savings or increased revenues can be made with additional capital investment. Meanwhile, to the operational staff, implementing simulation guided VSM can be far more convenient, spontaneous, interactive, and straightforward than the traditional paper-and-pencil based VSM. Simulation scenarios provide the flexibility required by the VSM to cope with the changes in combinations and permutations often encountered in this manufacturing process.

It is critical to remember that the VSM and related lean approaches require a factory floor focus, and the computer simulation analysis should not detract from this philosophy, nor should it substitute for or impede the flow of information from the factory floor. Rather, the simulation should be a guided tool that only enhances but not replaces the VSM by observing and quantifying long term effects that are not readily apparent on the floor, are available from traditional manufacturing information systems, or are too expensive or time consuming to experiment with on the floor. Also one should bear in mind that many benefits of the VSM and related lean approaches cannot be quantified with simulation modeling. Instilling proper organizational values, organization learning and employee empowerment systems, continuous improvement programs, and setting up a consistent organization structure as well as management information systems, are essential and mandatory elements of lean systems. If these management principles are not fully adopted along with 'simulation-based VSM', the VSM 
will not achieve all the benefits that could not be quantified and its performance could be inferior to the system it replaced.

\section{Conclusions and future study}

The VSM is a necessary but not a sufficient approach to analyze production system issues. Deficiencies often arise due to its deterministic nature, which make the traditional VSM not always straightforward to describe the current state of a manufacturing process and design a desired future state. Discrete event simulation is then utilized to enhance but not replace the VSM by visualizing better dynamic features of the future state before implementation. Different simulation scenarios are developed by observing the actual processing times of activities in the manufacturing process and then characterizing their variation by statistical distributions. A roadmap is offered to show how the VSM and the discrete event simulation are combined together to provide necessary information for improvement decision problems encountered in lean manufacturing implementation.

While applying the VSM some precautions should be observed. Since it gives an illustrative view of the process at any particular instant of time, it may capture the wrong representation at that particular instance, which may mislead decision-makers. Moreover, the VSM only suggests about the area of improvement. It does not discuss any rule of thumb to achieve the improvement. Despite the inadequacy, it is a really powerful tool. It links people, tools, metrics and even reporting requirements to achieve lean manufacturing. It provides clear and concise communication between management and shop floor teams about lean expectations, along with actual material and information flow. Hence, it allows understanding and continuously improving the understanding of lean concepts.

There are some interesting extensions for future works:

Firstly, future studies should integrate the approach with economic measures to express both value-added and non-value-added costs sustained through the process. The primary goal of the developed simulation model is to balance throughput, WIP and production lead time. Different objectives, such as cost minimization, machine availability maximization, should be explored to examine the performance of the simulation model.

Secondly, a more substantiate simulation model should be constructed to incorporate more practical issues by relaxing some assumptions. Simulation models are developed by observing the actual processing times of activities in the process and then characterizing their variation by statistical distributions. However, these times are recorded by a portion of the manufactured product types. It is assumed that the time data of the rest products will match with the actual operation time. More product types should be input to the simulation model for further validation. Furthermore, the yield rate is assumed to be $100 \%$ with no defect happened 
either during or at the end of the manufacturing process, which should have a fair impact on the simulated results.

An additional field for future research might be extending the current manufacturing process to evaluate the whole supply chain. One would find that it is necessary to map both intercompany and intra-company value-added streams. It is a far more focused and contingent view of the value-added process.

\section{Acknowledgements}

The authors greatly acknowledge the editor and the reviewers for their valuable comments and suggestions that have led to a substantial improvement of the paper.

\section{References}

Barker, R.C. (1994). The design of lean manufacturing systems using time based analysis. International Journal of Operations and Production Management, 14, 86-96. http://dx.doi.org/10.1108/01443579410068666

Bischak, D.P. (1996). Performance of a manufacturing module with moving workers. IIE Transactions, 28, 723-733.

Chan, F.T.S. (1995). Using simulation to predict system performance: a case study of an electro-phonetic deposition plant. Integrated Manufacturing Systems, 6, 27-38. http://dx.doi.org/10.1108/09576069510093451

Childerhouse, P. \& Towill, D.R. (2002). Analysis of the factors affecting real world value stream performance. International Journal of Production Research, 40, 3499-3518. http://dx.doi.org/10.1080/00207540210152885

Cho, K., Moon, I., \& Yun, W., (1996). System analysis of a multi-product, small-lot-sized production by simulation: a Korean Motor Factory case. Computers and Industrial Engineering, 30, 347-357. http://dx.doi.org/10.1016/0360-8352(96)00003-4

Detty, R.B. \& Yingling, J. (2000). Quantifying benefits of conversion from lean manufacturing with discrete events simulation: a case study. International Journal of Production Research, 38(2), 429-445. http://dx.doi.org/10.1080/002075400189509

Hines, P. \& Rich, N. (1997). The seven value stream mapping tool. International Journal of Operations and Production Management, 17, 46-64. http://dx.doi.org/10.1108/01443579710157989

Jones, D. \& Womack, J., (2000). Seeing the Whole: Mapping the Extended Value Stream. Lean Enterprise Institute, Massachusetts. 
Lian, Y.H. \& Van Landeghem, H. (2007). Analysing the effects of Lean manufacturing using a value stream mapping-based simulation generator. International Journal of Production Research, 45(13), 3037-3058. http://dx.doi.org/10.1080/00207540600791590

McDonald, T., Van Aken, E.M. \& Rentes, A.F., (2002). Utilizing simulation to enhance value stream mapping: a manufacturing case application. International Journal of Logistics: Research and Application, 5, 213-232. http://dx.doi.org/10.1080/13675560210148696

Park, Y.H., Matson, J.E., \& Miller, D.M. (1998). Simulation and analysis of the Mercedes-Benz All Activity Vehicle (AAV) production facility. Proceedings of 1998 Winter Simulation Conference, 921-926. http://dx.doi.org/10.1109/WSC.1998.745790

Persson, J.F. (2002). The impact of different levels of detail in manufacturing systems simulation models. Robotics and Computer-Integrated Manufacturing, 18, 319-325. http://dx.doi.org/10.1016/S0736-5845(02)00024-8

Pavnaskar, S.J., Gershenson, J.K. \& Jambekar, A.B. (2003). Classification scheme for lean manufacturing tools. International Journal of Production Research, 41, 3075-3090. http://dx.doi.org/10.1080/0020754021000049817

Prakash, A., \& Chen, M. (1995). A simulation study of flexible manufacturing systems'. Computers and Industrial Engineering, 28, 191-199. http://dx.doi.org/10.1016/03608352(94)00037-N

Rother, M. \& Shook, J. (1999). Learning to See: Value Stream Mapping to Create Value and Eliminate Muda. Lean Enterprise Institute, Massachusetts.

Shang, J.S., \& Tadikamalla, P.R. (1998). Multicriteria design and control of a cellular manufacturing system through simulation and optimization. International Journal of Production Research, 36, 1515-1528. http://dx.doi.org/10.1080/002075498193147

Sullivan, W.G., McDonald, T., \& Van Aken, E.M. (2002). Equipment replacement decisions and lean manufacturing. Robotics and Computer-Integrated Manufacturing, 18, 255-265. http://dx.doi.org/10.1016/S0736-5845(02)00016-9

Suri, R., \& Desiraju, R., (1997). Performance analysis of flexible manufacturing systems with a single discrete material-handling device. International Journal of Flexible Manufacturing Systems, 9, 223-249. http://dx.doi.org/10.1023/A:1007901028906

Welgama, P.S., \& Mills, R.G.J. (1995). Use of simulation in the design of a JIT system. International Journal of Operations \& Production Management, 15, 245-261. http://dx.doi.org/10.1108/01443579510099779

Womack, J. \& Jones, D. (1996). Lean Thinking - Banish Waste and Create Wealth in Your Corporation. New York: Simon \& Schuster. 


\section{Appendix}

After the initial analysis of the plant facility, two problematic areas are identified: uncertain capacities and inefficient Assembly and Packing area.

For the uncertain capacities, the detailed machine performance of one-old-one-new mills scenario can be generalized, as shown in Table A1. Given the current structure of just two lathe lines, this scenario provided the best overall performance considering capacity balance. Under this condition, only one of the old mills will not be needed to remain operating. Note that in this scenario, saw and assembly/packing work two shifts while the lathes and mills work three. Consequently, the lathe lines will be quite busy regarding the machine utilization.

\begin{tabular}{|l|c|c|c|c|}
\hline \multicolumn{1}{|c|}{ Machine } & Throughput (unit) & WIP (unit) & Wait time (min) & Utilization \\
\hline Saw & 2644 & 0.4 & 3 & $51.0 \%$ \\
\hline Lathe1A & 1320 & 15 & 475 & $89.0 \%$ \\
\hline Lathe1B & 1316 & 16 & 529 & $89.0 \%$ \\
\hline Work station & 2636 & 31 & 502 & $89.0 \%$ \\
\hline Lathe2A & 1320 & 2 & 55 & $75.0 \%$ \\
\hline Lathe2B & 1315 & 2 & 53 & $76.0 \%$ \\
\hline Work station & 2635 & 4 & 54 & $75.5 \%$ \\
\hline Mill-New & 2027 & 11 & 222 & $75.0 \%$ \\
\hline Mill_A & 523 & 8.8 & 607 & $72.0 \%$ \\
\hline Work station & 2550 & 19.8 & 280 & $74.6 \%$ \\
\hline Assembly/Packing & 2543 & 19 & 5 & 844 \\
\hline Total & & 74 & & \\
\hline
\end{tabular}

Table A1. Machine performance of one old one new mills scenario

Since the lathes are now the process bottleneck, another scenario is evaluated to consider the performance of potential introduction of a third set of lathes. That is three-lathes-three-mills scenario. This helps understand the effect a new lathe line would have on the throughput and also how many mills would be necessary to properly balance the line. The detailed machine performance of this scenario can be seen from Table A2. In this case, saw continues to work just two shifts while all other work stations work three.

The assembly and packing area has been redesigned as per the new layout shown in Figure 6, which dramatically reduces the time during the semi-finished tubular transportation in machining. 


\begin{tabular}{|l|c|c|c|c|}
\hline \multicolumn{1}{|c|}{ Machine } & Throughput (unit) & WIP (unit) & Wait Time (min) & Utilization \\
\hline Saw & 3360 & 0.6 & 4.6 & $65.0 \%$ \\
\hline Lathe1A & 1120 & 9.7 & 359 & $75.0 \%$ \\
\hline Lathe1B & 1120 & 8.3 & 305 & $76.0 \%$ \\
\hline Lathe1C & 1120 & 9 & 331 & $77.0 \%$ \\
\hline Work station & 3360 & 27 & 332 & $76.0 \%$ \\
\hline Lathe2A & 1120 & 1 & 41 & $64.0 \%$ \\
\hline Lathe2B & 1120 & 1 & 26 & $63.0 \%$ \\
\hline Lathe2C & 1120 & 1 & 48 & $64.0 \%$ \\
\hline Work Station & 3360 & 3 & 38 & $63.7 \%$ \\
\hline Mill-New & 2280 & 22 & 416 & $87.0 \%$ \\
\hline Mill_A & 505 & 12 & 997 & $84.0 \%$ \\
\hline Mill_B & 509 & 5 & 417 & $65.0 \%$ \\
\hline Work station & 3294 & 39 & 489 & $83.9 \%$ \\
\hline Assembly/Packing & 3293 & 75 & 63 & 927 \\
\hline Total & & 5 & & \\
\hline
\end{tabular}

Table A2. Machine performance of three lathes three mills scenario

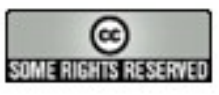

Article's contents are provided on a Attribution-Non Commercial 3.0 Creative commons license. Readers are allowed to copy, distribute and communicate article's contents, provided the author's and Journal of Industrial Engineering and Management's names are included. It must not be used for commercial purposes. To see the complete license contents, please visit http://creativecommons.org/licenses/by-nc/3.0/. 